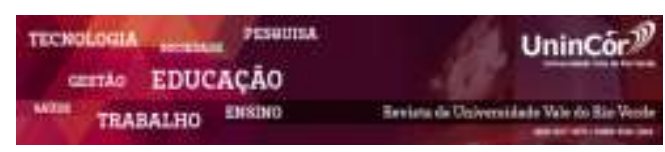

Revista da Universidade Vale do Rio Verde ISSN: 1517-0276 / EISSN: 2236-5362 v. 17 | n. 1 | Ano 2019

Bruno Lopes da Silva

Universidade Federal de Campina Grande (UFCG). brunolopesblds@outlook.com

Tainara Alexandre Sarmento Universidade Federal de Campina Grande (UFCG). tainara-alexandre@hotmail.com

Vanessa Érica da Silva Santos Universidade Federal de Campina Grande (UFCG). vanessa.erica@hotmail.com

Fernanda Beatryz Rolim Tavares Universidade Federal de Campina Grande (UFCG). nanda_sodi@hotmail.com

\section{CRISE PETROLÍFERA E O DESCASO FERROVIÁRIO: DA DEPENDÊNCIA AO COLAPSO}

\begin{abstract}
RESUMO
O presente artigo trata da problemática da crise petrolífera e da omissão brasileira no que diz respeito as malhas ferroviárias do país como uma alternativa para a agilizar e baratear os custos de transporte. Utilizou-se de metodologia bibliográfica e exploratória, objetivando explanar a Greve dos Caminhoneiros e suas consequências tanto dentro da sociedade quanto no ordenamento jurídico que a rege, no qual se analisou leis concernentes como a Lei de Greve, CLT e Lei Antitruste. Dessa forma, foi possível abordar as malhas ferroviárias como uma opção para diminuir as importações de derivados do petróleo e assim diminuir os custos com o qual o governo arca, dando ênfase ao descaso com o qual essa opção bastante beneficente é tratada e destacando os diversos benefícios do investimento em ferrovias. Vale ressaltar que a referida pesquisa pautou-se nos mais variados pesquisadores, revistas e demais meios necessários.
\end{abstract}

Palavras-chave:Petróleo. Ferrovias. Greve. Caminhoneiros. Governo.

\section{PETROLEUM CRISIS AND RAILWAY NEGLECT: FROM DEPENDENCE TO COLLAPSE}

\begin{abstract}
This article deals with the problems of the oil crisis and the Brazilian omission regarding the country 's railways as an alternative to speed up and reduce transportation costs. It was used a bibliographic and exploratory methodology, aiming to explain the Strike of the Truck drivers and their consequences both within the society and in the legal system that governs it, in which laws related such as the Law of Strike, CLT and Antitrust Law were analyzed. In this way, it was possible to approach rail networks as an option to reduce imports of petroleum products and thus reduce the costs with which the government arks, emphasizing the neglect with which this very beneficial option is treated and highlighting the various benefits investment in railways. It is noteworthy that this research was based on the most varied researchers, magazines and other necessary means.
\end{abstract}

Keywords:Petroleum. Railways. Strike. Truckers. Government.

Recebido em: 18/09/2018 - Aprovado em: 31/03/2019 - Disponibilizado em: 15/07/2019 


\section{INTRODUÇÃO}

Partindo dos acontecimentos que antecederam a Greve dos Caminhoneiros, esta pesquisa faz um contraponto do Efeito Dominó das ações econômico governamentais de cunho populista, aliadas a situação de descaso das ferrovias do país que culminaram na recente Greve dos Caminhoneiros, e as ações desagravantes para a situação presente e futura da economia. O referido tema foi escolhido considerando sua atualidade, proximidade com o leitor e relação contextual com a disciplina de Economia Geral e Política, abordada no curso de Direito.

Tem como objetivo geral situar o leitor nos precedentes e desdobramentos da Greve dos Caminhoneiros, bem como apresentar dados e fatos contextualizados na realidade do país e na realidade local de Sousa - PB e cidades circunvizinhas. E como objetivo específico a problematização da situação ferroviária com a Greve dos Caminhoneiros, apresentando-a como uma alternativa de aceleramento e barateamento dos custos do transporte no país.

$\mathrm{O}$ artigo está organizado em uma estrutura de tópicos e subtópicos, apresentando primeiramente a Greve dos Caminhoneiros em si, com seus antecedentes, desdobramentos e vicissitudes na realidade nacional e local, e por fim é feita uma discussão acerca da realidade da Malha Ferroviária brasileira.

\section{CONTEXTUAlizaÇÃo DA POLÍtica DOS COMBUSTÍVEIS}

Desde 2008, o Brasil adotou uma política de controle dos preços de combustíveis para combater a inflação, através da empresa Petrobras, de economia mista, tendo o governo amaioria de suas ações, que detém a supremacia de refino e importação de derivados do petróleo no país, e diante disso, tomou para si a responsabilidade pelo abastecimento do mercado interno.

Essa política de controle durou até 2014 quando os preços internacionais do petróleo se encontravam em alta, e diante da necessidade de reajustar os preços internos, e tendo em vista que, consequentemente o preço iria atingir os consumidores finais, gerando impactos inflacionários e políticos negativos, o governo decidiu conceder reduções fiscais a gasolina e ao diesel para que os reajustes nas refinarias não chegassem as bombas, assim como consta no procedimento administrativo movido pelo Ministério público contra o Conselho de Administração da Petrobras:

\begin{abstract}
"A partir de maio de 2008 todo aumento do preço da gasolina na refinaria foi compensado com a redução da alíquota da CIDE cobrada sobre o derivado, de modo que em julho de 2012 a alíquota foi totalmente zerada. Com a redução das alíquotas da CIDE a zero a partir de junho de 2012, os aumentos dos preços da gasolina nas refinarias começaram então a ser absorvidos, notadamente a partir de 2013, pelo caixa da própria PETROBRAS, pois o Conselho de Administração da empresa se negava a repassar os aumentos para os consumidores." (MPF, 2016, p.1)
\end{abstract}

No entanto, essa medida se mostrava extremamente prejudicial a economia da estatal, uma vez que não podia repassar aos consumidores os derivados pelo preço equivalente ao da importação, vendendo assim abaixo do montante que era comprado internacionalmente. Porquanto, o prejuízo consistiu principalmente na renúncia das receitas 
para baratear aos consumidores e na disparidade da compra e venda que cerceavam "comprar mais caro e vender mais barato", uma situação logicamente insustentável, o que consequentemente atingiu o interesse de investimentos privados na empresa, além de atrapalhar a capacidade de investimento da Petrobras.

O dano causado na economia da já referida empresa foi avaliado em bilhões, segundo estudos da Associação de investidores do Mercado de Capitais (AMEC), gerando uma dívida exorbitante devido a insuficiência no caixa ocasionado principalmente pelo desalinhamento dos preços.

Diante desse contexto que perdurou por anos a economia da estatal precisava se recuperar, e o primeiro passo foi deixar de adotar a política de controle dos preços, e assim passou a acompanhar as oscilações do mercado internacional, nivelando-se a cotação do petróleo e do dólar, em decorrência das importações, o que vem atingindo diretamente a população, gerando aumentos recordes em pouco espaço de tempo.

Uma curiosidade que cerceia esse ambiente é que o Brasil possui capacidade para produzir os derivados do petróleo sem que seja necessário a importação para abastecer o mercado interno, podendo se alinhar somente aos custos de produção e as receitas pertinentes e não ao mercado internacional.

$\mathrm{O}$ fato da produção de derivados de petróleo ser ausente no país gera uma falta de soluções diferente do aumento dos preços, uma vez que o país é obrigado a importar a gasolina, o diesel, e os demais derivados, tendo assim que seguir junto aos valores adotados externamente, sendo compelido as diversas variações internas que ocorreram durante os últimos tempos. O exposto pode ser confirmado a partir da nota técnica de número 194, de 26 de maio de 2018, do Departamento Intersindical de Estatística e Estudos Socioeconômicos (Dieese):

\begin{abstract}
“[...]O país passa a comprar no mercado internacional um bem que poderia produzir internamente. A produção de petróleo no Brasil, em abril de 2018, foi de 2,6 milhões de barris/dia (sem considerar $673 \mathrm{mil}$ barris de gás natural). Neste mesmo mês, as refinarias da Petrobras processaram 1,6 milhão de barris/dia e o consumo interno de derivados ficou em 2,2 milhões de barris/dia. Assim, mesmo produzindo 400 mil barris de petróleo a mais do que o necessário para atender ao consumo nacional, o país importou cerca de 600 mil barris de derivados/dia. Isso aconteceu porque a Petrobras está aumentando a exportação de petróleo cru e, ao mesmo tempo, reduzindo a utilização de suas refinarias. As refinarias da empresa possuem capacidade de refinar 2,4 milhões de barris/dia, mas estão utilizando apenas $68 \%$ dessa capacidade. Além disso, parte dessa produção de derivados está sendo direcionada para atender ao mercado externo." (DIEESE, 2018)
\end{abstract}

\subsection{Greve dos Caminhoneiros ou Crise do Diesel}

Devido ao intenso aumento ocorrido nos derivados do petróleo, como mencionado anteriormente, a locomoção no país tornou-se bastante cara, principalmente para aqueles que necessitam fazer longas viagens pelo país, como é o caso dos caminhoneiros que transportam mais da metade dos produtos duráveis e perecíveis consumidos em todo o país.

Diante dessa conjuntura, os caminhoneiros decidiram exercer seu direito fundamental estabelecido pela Constituição Federal vigente: “Art. $9^{\circ}$ É assegurado o direito de greve, competindo aos trabalhadores decidir 
sobre a oportunidade de exercê-lo e sobre os interesses que devam por meio dele defender".

No dia 21 de maio de 2018, iniciou-se a greve dos caminhoneiros que visava principalmente o congelamento no preço do diesel, o fim da cobrança de pedágio pelos eixos suspensos do caminhão, além da aprovação do projeto de Lei 528/2015 que tramita no Congresso Nacional e que regulariza a questão dos fretes através de uma tabela mínima de preços.

Os caminhoneiros bloquearam estradas, deixaram de fazer o transporte de produtos, causando assim, um enorme desabastecimento e instaurando uma verdadeira calamidade no país. Logo de início vários Estados aderiram à greve, somando tantos outros ao longo da mesma, paralisando, no primeiro momento, os grandes carregamentos e logo após não havendo acordo decidiram paralisar totalmente as estradas, impedindo o trafego de alimentos, carregamentos vivos, remédios, entre tantos outros. Ao longo da greve, diversas outras categorias uniram-se ao movimento, e alguns chegaram a pedir pela intervenção militar.

No decorrer da greve o preço do diesel foi reduzido, todavia uma "minoria radical" continuou o bloqueio das estradas, assim como afirmou o Presidente Michel Temer - em seu pronunciamento no Palácio do Planalto na sextafeira, 25 de maio de 2018- aumentando ainda mais os estragos derivados da mesma, levando o presidente a acionar as Forças Armadas para desbloquear as estradas, assim como o mesmo afirmou em seu pronunciamento; bem como também levou a Advocacia-Geral da União acionar o Supremo Tribunal Federal para declarar a greve ilegal, a aplicação de grandes multas, além da Polícia Federal, assim como afirmou em nota, abrir uma investigação acerca da suspeita de locaute, o que será abordado posteriormente.

Após a garantia de que a redução do diesel seria mantida e que as multas aplicadas seriam anuladas, no dia 31 de maio a greve teve seu fim, repercutindo gravemente em todo o país pela calamidade instaurada, além da reoneração da folha de pagamento em outros setores para equilibrar os danos da baixa.

2.3 Repercussão da greve em todo país e nas sublocalidades

Como dito antes, instaurou-se no país uma verdadeira calamidade durante a paralisação dos caminhoneiros. Devido à falta de previsão para o termino e a falta de transportadores, no dia 24 de maio, foram constatadas em quase todo o país filas gigantes em postos de gasolina, causando falta de combustível e prejudicando demasiadamente a população. Nesse sentido, é cabível destacar a suspensão das aulas em escolas e universidades, diminuição da circulação dos transportes públicos e privados, a suspensão da atuação em diversos hospitais e prontoatendimentos devido à falta de medicamentos, escassez e elevado aumento de preços em diversos Estados, além de muitos outros abalos, como os citados a seguir:

“[...] a Câmara Brasileira da Indústria
da Construção (CBIC) estima perdas
de $\mathrm{R} \$ 2,4$ bilhões no setor, enquanto a
indústria de frangos e suínos
contabiliza prejuízo de $\mathrm{R} \$ 1,8$ bilhão,
com lotes de carnes que não
conseguiram ser despachadas para o
mercado interno e para exportação. A
Associação Brasileira de Indústrias
Exportadoras de Carne (Abiec), por
sua vez, que cuida da parte de carne
bovina, crê que a paralisação de 
caminhoneiros tenha gerado danos de R\$ 620 milhões. A Confederação da Agropecuária (CNA) também acredita que a greve gerou $\mathrm{R} \$ 1,1$ bilhão aos produtores nacionais, incluindo os de leite [...]. Em média, são produzidos 95 milhões de litros de leite ao dia no Brasil, e a maioria está sendo descartado por falta de transporte." (TERRA, 2018)

Esses e outros dilemas enfrentados pela população, não atingiram somente as grandes metrópoles, como também os pequenos municípios, para se ter ideia do tamanho da proporção da greve.

\subsection{Possíveis ilícitos que permearam a greve}

É sabido que durante a greve dos caminhoneiros a Polícia Federal abriu uma investigação sobre a ocorrência de locaute, como já mencionado anteriormente, devido afirmativas do Ministro da Segurança Pública, Raul Jungmann, de acordo com Gerber e Marcante (2018):

\begin{abstract}
"Segundo ele, existem indícios de uma 'aliança' entre caminhoneiros autônomos e empresas de transporte para forçar o governo a reduzir o preço do diesel. O Conselho Administrativo de Defesa Econômica também anunciou que irá instaurar investigações para apurar os indícios de locaute na greve dos caminhoneiros." (GERBER; MARCANTE 2018).
\end{abstract}

Locaute nada mais é que o impedimento por parte dos empregadores para com os empregados de prosseguir com as atividades laborais com o fim de exterminar negociações ou reivindicações por parte desses últimos. É uma prática vedada pelo nosso ordenamento jurídico, principalmente pela Lei 7.783/1989, que dispõe sobre o exercício do direito à greve, regendo o seguinte: “Art. 17. Fica vedada a paralisação das atividades, por iniciativa do empregador, com o objetivo de frustrar negociação ou dificultar o atendimento de reivindicações dos respectivos empregados (lockout)."

Também pode-se enquadrar esta prática na Lei Antitruste:

“Art. 36. Constituem infração da ordem econômica, independentemente de culpa, os atos sob qualquer forma manifestados, que tenham por objeto ou possam produzir os seguintes efeitos, ainda que não sejam alcançados: [...]

IV - exercer de forma abusiva posição dominante."

Dispõe ainda, e dá-se providência, a Consolidação das Leis Trabalhistas (CLT) em seu Art. 722, que determina:

"Os empregadores que, individual ou coletivamente, suspenderem os trabalhos dos seus estabelecimentos, sem prévia autorização do Tribunal competente, ou que violarem, ou se recusarem a cumprir decisão proferida em dissídio coletivo, incorrerão nas seguintes penalidades:

a) multa de cinco mil cruzeiros a cinquenta mil cruzeiros;

b) perda do cargo de representação profissional em cujo desempenho estiverem;

c) suspensão, pelo prazo de 2 (dois) a 5 (cinco) anos, do direito de serem eleitos para cargos de representação profissional."

É de ampla percepção que ao ocorrer o locaute o empregador prioriza somente seus interesses próprios, colocando-os acima de quaisquer outros, inclusive os interesses dos subordinados, impondo suas decisões sem permitir que haja manifestações contrárias, de defesa, tonando a situação totalmente desequilibrada no que concerne a força dos envolvidos.

A pratica citada é proibida por entender que atinge diretamente ao direito de greve do empregado, no momento que impede que o mesmo seja exercido através do abuso de poder 
do empregador ao "fechar suas portas" impedindo que os demais possam reivindicar seus direitos, confrontando, dessa forma, os fundamentos constitucionais do nosso país que atribui valor social ao trabalho, além da própria dignidade da pessoa humanae da igualdade e bem-estar social perante todos.

No que diz respeito a greve ocorrida, alguns como o Ministro anteriormente citado, acreditam que tenha havido locaute, mas há controvérsias . Para muitos, o que houve não pode se configurar inteiramente como locaute, uma vez que locaute significa a greve dos empregadores em face dos empregados, e na greve dos caminhoneiros o que ocorreu foi a greve de todos em face do governo, com o objetivo comum de reduzir os preços para benefício compartilhado.

Nesse sentido, o advogado trabalhista Tiago Alves da Silva afirma em matéria publicada pela Revista Época Negócios, citado por Ribeiro (2018):

"No caso da greve dos caminhoneiros, parece haver um "interesse de ambos". Como a pauta levada ao governo é a redução no preço dos combustíveis, e na categoria temos tanto profissionais autônomos quanto empregados que são remunerados com base na produção e no custo, os comissionados têm uma baixa em seus rendimentos. [...] tanto a classe trabalhadora quanto a empregadora tem interesses sendo afetados, podendo-se dizer que em parte é uma greve, em outra locaute." (RIBEIRO, 2018).

Outra situação, ocorrida em meio a greve, já destacada, foram as variações de preços dos mais diversos produtos, principalmente os alimentícios e a gasolina. Este fato foi inicialmente justificado pela falta de oferta no mercado destes produtos, fazendo menção a lei daoferta e da procura. No entanto, a conduta do aumento de preços sem justa causa, é também vedada pelo nosso ordenamento jurídico, no Código de Defesa do Consumidor consta: "Art. 39. É vedado ao fornecedor de produtos ou serviços, dentre outras práticas abusivas: [...] X elevar sem justa causa o preço de produtos ou serviços." Entendeu-se que a greve não seria uma justa causa para o aumento dos preços, uma vez que nenhum aumento na origem dos produtos e seu decorrer havia sido verificado em tão pouco tempo.

\subsection{O Panorama Ferroviário}

Essa exacerbada preocupação com o preço das bombas por parte do governo e da população vem revelar outra preocupação não tão debatida: a das ferrovias. Indo contra a corrente de países com grandes dimensões territoriais como Rússia e Estados Unidos - que possuem uma malha ferroviária bem desenvolvida - no Brasil, cerca de $30 \%$ da malha ferroviária que ainda subsiste, foi construída por Dom Pedro II, e por isso não se adequaram bem as necessidades emergentes e cada vez mais frenéticas do País (CORDEIRO, 2007). Logo, desde 1950 o Brasil começou a investir intensamente em uma logística primordialmente rodoviária para $\mathrm{o}$ transporte de cargas, e na década de 1990, fez concessões para privatizar o setor ferroviário. Segundo um estudo do Instituto Brasileiro de Geografia e Estatística (IBGE) de 2015: 61,1\% das cargas são transportadas pelas rodovias, e $21 \%$ pela malha ferroviária.

Em 2014, o Plano CNT de Transporte e Logística 2014 sugeriu um investimento de $\mathrm{R} \$$ 448.833.266.882,40 bilhões para o setor ferroviário, chegando a ser timidamente superior 
ao das rodovias no mesmo documento, porém, na prática não é proporcional, uma vez que asferrovias custam caro para saírem do papel. Acerca disso, diz Gustavo Bambini, presidente da Associação Nacional de Transporte Ferroviário (ANTF):

"Para se ter uma ideia, o custo de construção de apenas um quilômetro de ferrovia é de U\$ 1,5 milhão. Sem contar as pontes e viadutos, que muitas vezes são necessários. [...] O preço médio para a construção de um quilômetro de rodovia é de U\$ 200 mil. Ou seja, o valor final de uma ferrovia sai sete vezes mais caro que o de uma rodovia". (BAMBINI, 2014)

Atualmente, se mostra verdadeira a insuficiência do valor para fomentar a expansão da malha ferroviária. Conforme dados obtidos dos Boletins Estatísticos da CNT (2015, 2018), de Janeiro de 2015 para Janeiro de 2018, a extensão em Km da malha ferroviária Brasileira diminuiu aprox. 1,18\%:

Tabela 1 - Extensão da Malha Ferroviária Brasileira $(\mathrm{Km})$

\begin{tabular}{ll}
\hline Total Nacional em Janeiro de 2015 & 30.129 \\
\hline Total Nacional em Janeiro de 2018 & 29.774 \\
\hline Fonte: Adaptado de CNT $(2015,2018)$ &
\end{tabular}

Fonte: Adaptado de CNT $(2015,2018)$

E em relação ao Plano CNT de Transporte e Logística Plano do CNT de 2014, foi averiguado pela Pesquisa CNT de Ferrovias 2015 que, no ritmo em que estava andando os investimentos, seriam necessários mais 54 anos para concluir somente os projetos prioritários do plano. A situação é ainda mais involutiva quando se analisa um período de tempo maior acerca da extensão das malhas ferroviárias: do apogeu das ferrovias (1960) até os dias atuais constata-se uma queda de $25,57 \%$ :

Tabela 2 - Extensão da Malha Ferroviária Brasileira $(\mathrm{Km})$

Total Nacional em 1960

Aprox. 40.000

Total Nacional em Janeiro de 2018

29.774

Fonte: Adaptado de O Tempo

Esse investimento insuficiente no aludido setor reflete diretamente no preço dos combustíveis, por uma série de fatores em cadeia, uma vez que as escassas ferrovias que ainda transportavam passageiros, em sua maioria fecharam, sendo que atualmente mais de $90 \%$ da malha ferroviária é destinada somente a cargas. Essa realidade aliada ao crescimento da indústria de carros favorece o aumento do fluxo de passageiros em rodovias, que sobrecarrega e torna mais lento o transporte de cargas. Cargas como do setor agropecuário, que se beneficiariam com isso e evitaria o prejuízo que soma mais de R 4 bilhões de reais (IPEA, 2018), todavia, a malha ferroviária é explorada em sua maior parte para o minério de ferro. $\mathrm{E}$ isso não se resume a gestão governamental e economia, o fator político também está presente, uma vez que a inauguração de uma rodovia acontece com mais rapidez, e a de uma ferrovia pode acontecer no mandato do candidato adversário, devido seu tempo mais elevado para construção.

Dado o exposto, fica claro o descaso com a Malha Ferroviária do país. Acrescenta-se o fato de que há críticas ao governo quanto aos contratos de concessão e também às próprias concessionárias em não aderirem bem ao Direito de Passagem, e segundo um levantamento de 2018 da Confederação Nacional da Indústria (CNI): mais de 30\% dos 
trilhos não são utilizados e cerca de $23 \%$ estão sem condições de serem utilizados.

2.6 Um sustentáculo possível para o futuro

A longo prazo, embora as ferrovias sejam mais caras de se investir, elas tem frete mais barato e eficaz para cargas de longas distâncias, além de ter uma logística mais canalizada, o que desatolaria os caminhões. Além disso, as aludidas malhas poluem menos o meio ambiente, incentivam o turismo e tem durabilidade maior que as malhas rodoviárias, como pode-se constatar abaixo:

Gráfico 1 - Vida Útil das Malhas Rodoviária e Ferroviária(em Anos)

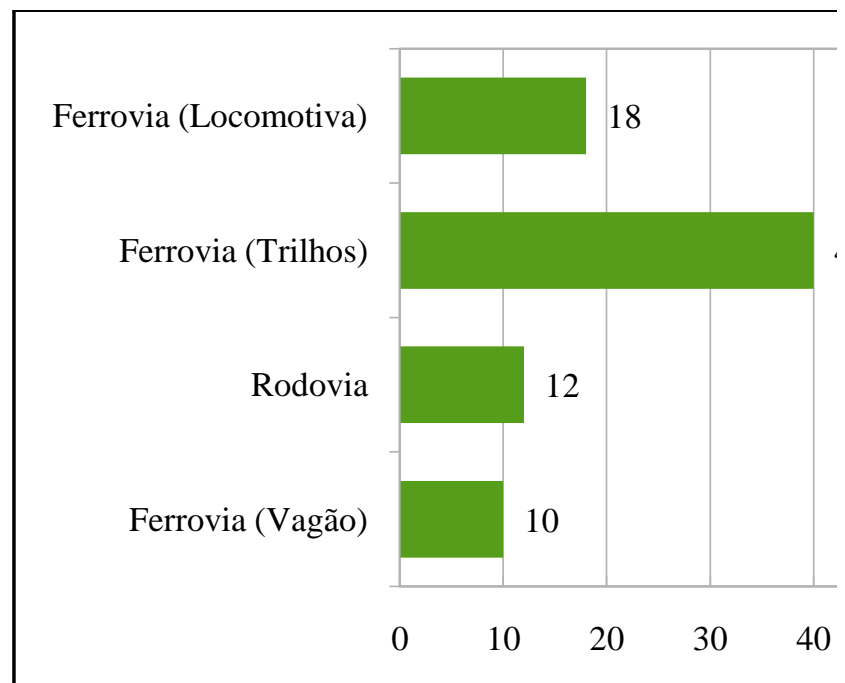

Fonte: Adaptado de CNT $(2015,2017)$

Logo, percebe-se como é vantajoso o investimento em ferrovias e que poderia evitar recente colapso no país. O economista Benedito Rodrigues (2017) destaca que a reestruturação da malha ferroviária pode até ajudar a aquecer a economia do Brasil com o Mercosul. E segundo Clésio Andrade (2015), Presidente da CNT, "um dos caminhos para o Brasil retomar o desenvolvimento e permitir maior integração nacional é a priorização do transporte ferroviário, que levará ao equilíbrio da matriz de transporte de cargas e a consequente redução dos custos logísticos" (grifos nossos).

\section{CONSIDERAÇÕES FINAIS}

Diante do exposto, ficou claro como uma política econômica que visa a aceitação popular sem considerar os impactos ao erário público pode ser danosa à Economia, acarretando prejuízos e forçando o governo a adotar políticas de exportação com preços muito baixos. Tudo isso faz parte de um grande efeito Dominó que culminou com a Greve dos Caminhoneiros.

Acerca da aludida greve, constatou-se que tanto o fornecedor como o consumidor foram prejudicados pela mesma: tanto nos grandes centros urbanos quanto nos menores e mais locais, e que durante a greve houve suspeitas de infrações contra normas do Ordenamento Jurídico Brasileiro quanto a economia (Lei Antitruste), a relação trabalhista (CLT), quanto a própria greve (Lei de Greve) devido ao suposto locaute,e quanto a relação consumerista devido ao aumento de preços (Código de Defesa do Consumidor).

Logo, se tornou clara a desbalanceada necessidade e dependência do país sobre os caminhões, e que a afirmação "Sem caminhão, o Brasil para!" é verdadeira, afinal, a logística de cargas da Nação é concentrada nas rodovias em detrimento das ferrovias, o que encarece o frete, polui mais o meio ambiente e faz com que as rodovias durem menos e causem mais gastos para os cofres públicos para a sua manutenção. Com o acontecimento da greve, se tornou mais enfática a importância das malhas ferroviárias, quanto a essas, foi constatado que estão em 
processo de diminuição de sua extensão, pois não tem investimento suficiente, sendo que parte da extensão não é utilizada, e outra parte é inutilizável.

Enfim, foi verificado como as ferrovias tem maior durabilidade e menor impacto ambiental do que as rodovias, constituindo-se em investimentos necessários e de longo prazo, pois se as mesmas recebessem mais atenção do Governo e fossem utilizadas devidamente para o transporte de cargas, não seria necessário a maciça importação de derivados de petróleo (como o óleo Diesel), o que reduziria a pressão sobre os caminhões, baratearia os custos dos combustíveis nas bombas e agilizaria os transportes de cargas pelo Brasil.

\section{REFERÊNCIAS}

BRASIL. Consolidação das Leis de Trabalho. Decreto-Lei ${ }^{\circ}$ 5.442, de 01.mai.1943. Disponível em: http://www.planalto.gov.br/ccivil_03/decretolei/Del5452.hhtm>. Acesso em: 01 jul. 2018.

BRASIL. Constituição Federal de 1988. Promulgada em 5 de outubro de 1988. Disponível em $<$ http://www.planalto.gov.br/ccivil_03/constituicao/co nstituição.htm> Acesso em: 01 jul. 2018.

BRASIL. Lei Antitruste, de 30 de novembro de 2011. Disponível em: <http://www.planalto.gov.br/ccivil_03/_ato20112014/2011/Lei/L12529.htm>. Acesso em: 01 jul. 2018.

CONFEDERAÇÃO NACIONAL DA INDÚSTRIA. Um terço das ferrovias do país está inutilizada, aponta CNI. 2018. Disponível em: <https://noticias.portaldaindustria.com.br/noticias/infr aestrutura/um-terco-das-ferrovias-do-pais-estainutilizada-aponta-cni/>. Acesso em 30 jun. 2018.

CONFEDERAÇÃO NACIONAL DO TRANSPORTE. Boletim Estatístico - CNT Janeiro 2015. 2015. Disponível em: <http://cms.cnt.org.br/Imagens\%20CNT/BOLETIM\% 20ECONOMICO/2015/201502\%20-

$\%$ 20Boletim\%20Estatistico\%20CNT\%20-

\%20Janeiro.pdf>. Acesso em: 29 jun. 2018.
CONFEDERAÇÃO NACIONAL DO

TRANSPORTE. Boletim Estatístico - CNT -

JANEIRO 2018. 2018. Disponível em:

<http://cms.cnt.org.br/Imagens\%20CNT/BOLETIM\% 20ESTAT\%C3\%8DSTICO/BOLETIM\%20ESTAT\% C3\%8DSTICO $\% 202018 /$ Boletim\%20Estat\%C3\%AD stico\%20-\%2001\%20-\%202018.pdf>. Acesso em: 29 jun. 2018.

\section{CONFEDERAÇÃO NACIONAL DO}

TRANSPORTE. Gargalos reduzem eficiência do transporte ferroviário. 2015. Disponível em: <http://cms.cnt.org.br/Imagens\%20CNT/Site\%202015 /Pesquisas\%20PDF/Pesquisa\%20CNT\%20de\%20Ferr ovias\%202015\%20resumo.pdf>. Acesso em: 30 jun. 2018.

\section{CONFEDERAÇÃO NACIONAL DO}

TRANSPORTE. Plano CNT de Transporte e

Logística 2014. 2014. Disponível em:

<http://cms.cnt.org.br/Imagens\%20CNT/PDFs\%20C NT/Plano\%20CNT\%20de\%20Log\%C3\%Adstica/Mat erial\%20imprensa\%20final.pdf $>$. Acesso em: 29 jun. 2018.

\section{CONFEDERAÇÃO NACIONAL DO}

TRANSPORTE. Por que os pavimentos das rodovias do Brasil não duram?: Resumo. 2017. Disponível em:

<http://cms.cnt.org.br/Imagens\%20CNT/PDFs\%20C NT/Estudos\%20CNT/resumo_pavimentos_nao_dura m.pdf $>$. Acesso em: 01 jul. 2018.

CONFEDERAÇÃO NACIONAL DO

TRANSPORTE. Transporte e Economia - O

Sistema Ferroviário Brasileiro. 2015. Disponível em:

<http://cms.cnt.org.br/Imagens\%20CNT/Site\%202015 /Pesquisas\%20PDF/Transporte\%20e\%20Economia\% 20\%E2\%80\%93\%20O\%20Sistema\%20Ferrovi\%C3\% A1rio\%20Brasileiro.pdf>. Acesso em 01 jul. 2018.

CORDEIRO, Tiago.O Brasil tivesse uma malha ferroviária decente?.Superinteressante, 2007, atualizado em 2016. Disponível em <https://super.abril.com.br/saude/o-brasil-tivesseuma-malha-ferroviaria-decente/>. Acesso em: 29 jun. 2018.

COSTA, Benedito Rodrigues da.Ferrovia é a solução.Correio do Estado, 2017. Disponível em: <https://www.correiodoestado.com.br/opiniao/benedit o-rodrigues-da-costa-ferrovia-e-a-solucao/310086/>. Acesso em: 30 jun. 2018.

DIEESE. Nota Técnica ${ }^{\circ} 194$ de 26 de maio de 2018. A escalada do preço dos combustíveis e as recentes escolhas da política do setor de petróleo. Disponível em:

<https://www.dieese.org.br/notatecnica/2018/notaTec 194PrecosCombustiveis.pdf>. Acesso em: 22 ago. 2018.

FRANÇA, Valéria. Malha ferroviária produtiva do Brasil é a mesma do Império. Estadão, 2014.

Disponível em:

<https://economia.estadao.com.br/noticias/geral,malha 
-ferroviaria-produtiva-do-brasil-e-a-mesma-doimperio,1539689>. Acesso em: 29 jun. 2018.

GERBER, D.; MARCANTE, M. Greve de caminhoneiros e as suspeitas de locaute. ESTADÃO, Política. 2018. Disponível em: <https://politica.estadao.com.br/blogs/faustomacedo/greve-de-caminhoneiros-e-as-suspeitas-delocaute/>. Acesso em: 18 set. 2018.

GONTIJO, Juliana. Estradas de ferro encolheram 25\% desde a década de 60. O Tempo, 2018.

Disponível em:

<https://www.otempo.com.br/capa/economia/estradas -de-ferro-encolheram-25-desde-a-d\%C3\%A9cada-de60-1.1854717>. Acesso em 30 jun. 2018.

INFOGRÁFICO - A Malha Ferroviária Brasileira Parte 2.Blog Logística, 2016. Disponível em: <https://www.bloglogistica.com.br/mercado/infografi co-a-malha-ferroviaria-brasileira-parte-2/>. Acesso em: 29 jun. 2018.

MINISTÉRIO PÚBLICO FEDERAL - MPF. $3^{\mathrm{a}}$ Câmara de Coordenação e Revisão do Ministério Público Federal Grupo de Trabalho Energia e Combustíveis. RELATÓRIO FINAL -

Procedimento administrativo $\mathbf{n}^{\circ}$

1.00.000.007679/2014-16. 2016. Disponível em:

<http://www.mpf.mp.br/pgr/documentos/copy_of_GT EnergiaeCombustveisRelatrioFinal.pdf >. Acesso em: 18 set. 2018.

O TEMPO - Editora de Arte. Brasil fora dos trilhos. Formato JPEG. Disponível em:

<https://www.otempo.com.br/infogr\%C3\%A1 ficos/br asil-fora-dos-trilhos-1.1854802>. Acesso em 30 jun. 2018.

RIBEIRO, J. Greve dos caminhoneiros é 'locaute'? Entenda o significado do termo. ÉPOCA NEGÓCIOS, 2018. Disponível em:

<https://epocanegocios.globo.com/Brasil/noticia/2018 /05/greve-dos-caminhoneiros-e-locaute-entenda-osignificado-do-termo.html>. Acesso em: 18 set. 2018.

\section{TERRA NOTÍCIAS. Jornal: greve de} caminhoneiros causa prejuízo de $\mathbf{R} \$ 10$ bi. 2018. Disponível em: <https://www.terra.com.br/noticias/brasil/greve-decaminhoneiros-ja-causa-prejuizo-de-r-10bilhoes,e2a49e666d57cfb34d10c408b8c89159eip5k39 h.html>. Acesso em: 18 set. 2018.

\section{Bruno Lopes da Silva}

Graduando em Ciências Jurídicas e Sociais pela Universidade Federal de Campina Grande (UFCG).

\section{Tainara Alexandre Sarmento}

Graduanda em Ciências Jurídicas e Sociais pela Universidade Federal de Campina Grande (UFCG).

\section{Vanessa Érica da Silva Santos}

Graduada em Ciências Jurídicas e Sociais pela Universidade Federal de Campina Grande (UFCG), Especialista em Direito do Trabalho pela UNOPAR, Pós-graduanda (especialização) em Direito Penal e Processo Penal pela UFCG, Pós-graduanda (especialização) em Gestão Pública pelo IFPB e Mestranda em Sistemas Agroindustriais CCTA/UFCG, Professora Substituta da UFCG

\section{Fernanda Beatryz Rolim Tavares}

Graduada em Ciências Contábeis pela Universidade Federal de Campina Grande (UFCG), Especialista em Gestão Ambiental pela UFCG, Pós-graduanda (especialização) em Gestão Pública pelo IFPB, Pósgraduanda (especialização) em Contabilidade para Gestão Pública e Empresarial. Mestre em Sistemas Agroindustriais - CCTA/UFCG. 